Artigo

\title{
Solution of the Atmospheric Diffusion Equation with Longitudinal Wind Speed Depending on Source Distance
}

\author{
Davidson Martins Moreira ${ }^{1}$, Taciana Toledo de Almeida Albuquerque ${ }^{2}$ \\ ${ }^{1}$ Centro Integrado de Manufatura e Tecnologia, Serviço Nacional de Aprendizagem Industrial, \\ Salvador, BA, Brazil. \\ ${ }^{2}$ Universidade Federal de Minas Gerais, Belo Horizonte, MG, Brazil.
}

Received: 20/3/2015 - Accepted: 23/7/2015

\begin{abstract}
An integral semi-analytical solution of the atmospheric diffusion equation considering wind speed as a function of both downwind distance from a pollution source and vertical height is presented. The model accounts for transformation and removal mechanisms via both chemical reaction and dry deposition processes. A hypothetical dispersion of contaminants emitted from an urban pollution source in the presence of mesoscale winds in an unstable atmospheric boundary layer is showed. The results demonstrate that the mesoscale winds generated by urban heat islands advect contaminants upward, which increases the intensity of air pollution in urban areas.
\end{abstract}

Keywords: urban heat island, mesoscale wind, semi-analytical model, atmospheric boundary layer.

\section{Solução da Equação de Difusão Atmosférica com Vento Longitudinal Dependente da Distância da Fonte}

\begin{abstract}
Resumo
Neste trabalho, é apresentada uma solução integral semi-analítica da equação de difusão atmosférica considerando a velocidade do vento como função da distância longitudinal e vertical da fonte poluidora. O modelo leva em consideração os mecanismos de remoção e transformação via deposição seca e reação química. Uma hipotética fonte de emissão de contaminantes urbana na presença de ventos de mesoescala em uma camada limite instável é mostrada. Os resultados sugerem que os ventos de mesoescala gerados pela ilha de calor urbana advectam os contaminantes para cima, aumentando a intensidade da poluição atmosférica em áreas urbanas.
\end{abstract}

Palavras-chave: ilha de calor urbana, vento de mesoescala, modelo analítico, camada limite atmosférica.

\section{Introduction}

The atmospheric dispersion equation has long been used to describe the transport of air contaminants in a turbulent atmosphere. Analytical and semi-analytical solutions to this equation were the first and remain the most convenient methods for modeling air pollution because many atmospheric problems can be studied. However, little attention has been given to the atmospheric problems to find solution of this equation for wind speed as a function of both downwind distance $(x)$ from the source and the vertical height $(z)$ above the ground, mainly due to the mathematical complexity problem involved. We are aware of analytical and semi-analytical solutions existence in the literature, but for specific and particular problems. Among them, we mention the works of Rounds (1955), Smith (1957), Scriven and Fisher (1975), Demuth (1978), van Ulden (1978), Nieuwstadt and de Haan (1981), Sharan et al. (1996), Lin and Hildemann (1997), Wortmann et al. (2005), Sharan and Modani (2006), Sharan and Kumar (2009). In all of these models, the wind speed is either a power law or logarithmic profile of vertical height and, similarly, the eddy diffusivity has been assumed either a power law or a parabolic profile of $z$ or a function of downwind distance from the source. However, none of these provides a systematic approach to find the solution with the generalized functional forms of wind speed and eddy diffusivity. At this point, it is important to mention that a solu-

Autor de correspondência: Davidson Martins Moreira, davidson@pq.cnpq.br. 
tion of the advection-diffusion equation can be written an integral form and also in series formulations with the same main property that both solutions are equivalent (Moreira et al., 2010). Furthermore, analytical and semi-analytical solutions are very important to understand and describe the physical phenomenon, since they are able to take into account all the parameters of a problem and investigate their influence. Besides, while the preexisting numerical models require improvements for addressing more realistic situations, it is helpful to first examine a few possible analytical (or semi-analytical) solutions to obtain a framework and a set of test solutions. These solutions are useful for a variety of applications, such as providing approximate analyses of alternative pollution scenarios, conducting sensitivity analyses for investigating the effects of various parameters or processes involved in contaminant transport, extrapolation over large time scales and distances where numerical solutions may be impractical, serving as screening models or benchmark solutions for more complex transport processes that cannot be solved exactly, and for validating more comprehensive numerical solutions to the governing transport equations.

Focusing our attention in this direction, the novelty of this work consists of a semi-analytical solution of a twodimensional advection-diffusion equation considering longitudinal wind speed depending on the $x$ and $z$ variables in an air pollution problem. The literature does not present experimental data to compare with the solution obtained in this work. Thus, to compare with a solution obtained in this work we use the results obtained by Agarwal and Tandon (2010), that present a numerical solution to the twodimensional advection-diffusion equation considering an idealized situation with wind speed depending on $x$ and $z$ variables. This idealized study tries to show the effect of urban heat islands on urban air pollution through mathematical modeling. An attempt at such a solution is presented here in the form of a steady state two-dimensional mathematical model that allows for examining the dispersion of air contaminants in the urban atmosphere under the cumulative effect of large-scale and mesoscale winds. The twodimensional heat island problem is an idealization; the mesoscale winds considered in the present study are only representative of a special type of wind.

The remainder of this paper is organized as follows. In section 2, the solution of the advection-diffusion equation is presented. In section 3 , numerical results are reported. Lastly, in section 4, the conclusions of this study are presented.

\section{The Model}

It is well known that an analytical or semi-analytical solution can be expressed in either an integral or series formulation (Moreira et al., 2010). Assuming that these solutions are equivalent, results attained from an integral solution that considers the longitudinal wind speeds as a function of $x$ and $z$ variables and realistic vertical eddy diffusivity are presented in air pollution problems.

For a Cartesian coordinate system in which the $x$ direction coincides with the direction of the mean wind, the steady state advection-diffusion equation can be written as follows (Moreira and Vilhena, 2009):

$$
\begin{aligned}
& u \frac{\partial \bar{c}}{\partial x}+v \frac{\partial \bar{c}}{\partial y}+w \frac{\partial \bar{c}}{\partial z}=\frac{\partial}{\partial x}\left(K_{x} \frac{\partial \bar{c}}{\partial x}\right)+ \\
& \frac{\partial}{\partial y}\left(K_{y} \frac{\partial \bar{c}}{\partial y}\right)+\frac{\partial}{\partial z}\left(K_{z} \frac{\partial \bar{c}}{\partial z}\right)-\lambda \bar{c}
\end{aligned}
$$

where $\bar{c}$ denotes the averaged concentration, $u, v$, and $w$ are the mean wind speeds in the $x$ (longitudinal), $y$ (lateral) and $z$ (vertical) directions, $K_{x}, K_{y}$ and $K_{z}$ (in this study depending only on $z$ ) are the eddy diffusivities in the respective directions and $\lambda$ is a constant first-order depletion parameter that considers the relevant removal mechanisms, such as chemical reactions, rainout/washout, and artificial mechanisms that prevail in the atmosphere. To obtain the semianalytical solution proposed in this study, Eq. (1) is integrated from $-\infty$ to $+\infty(\bar{c} \rightarrow 0$ for $y \rightarrow-\infty$ and $y \rightarrow+\infty)$ in the cross-wind direction (neglecting longitudinal diffusion, because the advection transport term in the $x$ direction is dominant over the diffusive term) to obtain the following relationship (Moreira and Vilhena, 2009):

$$
u \frac{\partial c^{y}}{\partial x}+w \frac{\partial c^{y}}{\partial z}=\frac{\partial}{\partial z}\left(K_{z} \frac{\partial c^{y}}{\partial z}\right)-\lambda c^{y}
$$

where $c^{y}$ is the integrated cross-wind concentration.

In this study, the contaminant is transported horizontally by a large-scale wind, which is assumed to be function of altitude, and also function of the horizontal and vertical mesoscale winds. The mesoscale winds represent local winds that are caused by a heat source, which is an infinite cross-wind linear heat source parallel to the contaminant source in this study. For details see the works of Dilley and Yen (1971) and Agarwal and Tandon (2010). Therefore, the Eq. (2) can be written as follows:

$$
\left(u_{l}+u_{e}\right) \frac{\partial c^{y}}{\partial x}+w_{e} \frac{\partial c^{y}}{\partial z}=\frac{\partial}{\partial z}\left(K_{z} \frac{\partial c^{y}}{\partial z}\right)-\lambda c^{y}
$$

where $u_{l}$ is the large-scale wind in the $x$ (horizontal) direction and $u_{e}$ and $w_{e}$ are the mesoscale wind components in the $x$ and $z$ directions, respectively.

The heat island effect of a city causes air to rise above the center of the heat island. This rising air produces a surface influx of air from the surrounding area; large thermally induced convective currents are also generated (Dilley and Yen, 1971). These effects produce mesoscale winds.

In this work, the large-scale wind $u_{l}$ is parameterized as a function of height $z$ in the manner suggested by Lin and Hildemann (1997) for simplicity: 


$$
u_{l}=u(z)=u_{r}\left(\frac{z}{z_{r}}\right)^{\alpha}
$$

where $u_{r}$ is the measured wind speed at a reference height $z_{r}$ and $\alpha$ is a constant that depends on the atmospheric stability. The mathematical formulations of the mesoscale horizontal and vertical wind components within the range of valid values are used as suggested by Dilley and Yen (1971). Thus, the following relationships are used in this study:

$$
u_{e}=-a x\left(\frac{z}{z_{r}}\right)^{\alpha}
$$

and

$$
w_{e}=\frac{a z}{(\alpha+1)}\left(\frac{z}{z_{r}}\right)^{\alpha}
$$

where $a$ is a proportionality constant (unit: $1 / \mathrm{s}$ ). The expressions for $u_{l}, u_{e}$ and $w_{e}$ are utilized within the surface layer. Above this layer, these values are considered to be constant with height.

Furthermore, the wind speed component represented in Eq. (3) can be written as follows:

$$
\begin{aligned}
& u_{l}+u_{e}=u_{r}\left(\frac{z}{z_{r}}\right)^{\alpha}-a x\left(\frac{z}{z_{r}}\right)^{\alpha}= \\
& \left(1-\frac{a x}{u_{r}}\right)\left(\frac{z}{z_{r}}\right)^{\alpha} u_{r}=u(x, z)
\end{aligned}
$$

and $u(x, z)=f(x) \cdot g(z)$, where $f(x)=\left(1-a x / u_{r}\right)$ is a nondimensional function and $g(z)=u(z)=\left(z / z_{r}\right)^{\alpha}$ is a dimensional function $\left[\mathrm{LT}^{-1}\right]$.

The vertical eddy diffusivity $K_{z}$ is parameterized as a function of height $z$ following the work of Moreira et al. (2005b):

$$
\begin{aligned}
& K_{z}=K_{z}(z)=0.22 w_{*} h\left(\frac{z}{h}\right)^{1 / 3}\left(1-\frac{z}{h}\right)^{1 / 3} \times \\
& {\left[1-\exp \left(\frac{4 z}{h}\right)-0.0003 \exp \left(\frac{8 z}{h}\right)\right]}
\end{aligned}
$$

where $h$ is the atmospheric boundary layer (ABL) height and $\mathcal{w}_{*}$ is the convective velocity. The eddy diffusivity parameterization is based on turbulent kinetic energy spectra and Taylor's diffusion theory.

To solve Eq. (3), both source and boundary conditions are needed. Therefore, zero flux is assumed at the ground and at the top of the ABL. Moreover, a source with emission rate $Q$ at height $H_{s}$ is also assumed to obtain the following:

$$
\begin{aligned}
& K_{z} \cdot \frac{\partial c^{y}}{\partial z}=0 \text { at } z=h \\
& K_{z} \cdot \frac{\partial c^{y}}{\partial z}=V_{d} c^{y} \text { at } z=z_{0}
\end{aligned}
$$

and

$$
\left(u_{l}+u_{e}\right) c^{y}(0, z)=Q \delta\left(z-H_{s}\right) \text { at } x=0
$$

where $z_{0}$ is the roughness length, $V_{d}$ is the deposition velocity and $\delta$ is the Dirac delta function.

By considering the dependence of the $K_{z}(z)$ and wind speed (i.e., $u(x, z)$ and $w(z))$ profiles on height $z$, the height of the ABL $h$ is discretized into $N$ sub-intervals such that within each interval, the average values in the vertical are used. Therefore, the solution to Eq. (3) is reduced to the solution of $N$ equations of the following type:

$$
\begin{aligned}
& u_{n} \frac{\partial c_{n}^{y}}{\partial x}+\bar{w}_{e}^{n} \frac{\partial c_{n}^{y}}{\partial z}=\bar{K}_{n} \frac{\partial^{2} c_{n}^{y}}{\partial z^{2}}-\lambda c_{n}^{y} \\
& z_{n} \leq z \leq z_{n+1}, \quad n=1: N
\end{aligned}
$$

where $c_{n}^{y}$ denotes the concentration, $\bar{w}_{e}^{n}$ is the average vertical mesoscale wind and $\bar{K}_{n}$ is the average vertical eddy diffusivity, in the $n^{\text {th }}$ sub-interval. Moreover,

$$
u_{n}=f(x) \frac{1}{z_{n+1}-z_{n}} \int_{z_{n}}^{z_{n+1}} g(z) d z=f(x) \bar{u}_{n}
$$

and

$$
f(x)=\left(1-\frac{a x}{u_{r}}\right)=j(x)
$$

A change of variables is used to obtain a solution to Eq. (11) (Crank, 1979, Moreira et al., 2014). The new space variable $x^{*}$ is defined by the following transformation:

$$
x^{*}=\int_{0}^{x} \frac{d x^{\prime}}{j\left(x^{\prime}\right)}=-\frac{u_{r}}{a} \ln \left(1-\frac{a x}{u_{r}}\right)
$$

The dimension of $x^{*}$ is same as $x$ [L]; therefore, $x^{*}$ is considered to be a new space variable. Because $j(x)>0$, the function $x \rightarrow x^{*}$ is an increasing function of $x$ that vanishes at $x=0$. Thus, the nature of the condition at $x=0$ does not change in the new domain.

However, before providing additional details regarding the solution procedure, the obtained solution to Eq. (11) is valid only for the downwind range $0<x<u_{r} / a$ of the large-scale and mesoscale winds; however, the range of validity increases as the mesoscale winds approach zero.

The equation, combined with the necessary source and boundary conditions, becomes the following in the new space: 


$$
\bar{u}_{n} \frac{\partial c_{n}^{y}}{\partial x^{*}}+\bar{w}_{e}^{n} \frac{\partial c_{n}^{y}}{\partial z}=\bar{K}_{n} \frac{\partial^{2} c_{n}^{y}}{\partial z^{2}}-\lambda c_{n}^{y}
$$

To account for vertically inhomogeneous turbulence (dependent on $z$ ), continuity conditions are imposed for the concentration and concentration flux at the interfaces:

$$
c_{n}^{y}=c_{n+1}^{y} \quad n=1,2, \ldots,(N-1)
$$

and

$$
K_{n} \frac{\partial c_{n}^{y}}{\partial z}=K_{n+1} \frac{\partial c_{n+1}^{y}}{\partial z} \quad n=1,2, \ldots,(N-1)
$$

These conditions must be considered to uniquely determine the $2 N$ arbitrary constants appearing in the solution to the set of equations defined in Eq. (15).

Applying the Laplace transform to Eq. (15) results in the following relationship:

$$
\begin{aligned}
& \frac{d^{2}}{d z^{2}} \widehat{c}_{n}(s, z)-\frac{\bar{w}_{e}^{n}}{\bar{K}_{n}} \frac{d}{d z} \widehat{c}_{n}(s, z)- \\
& \frac{\left(\bar{u}_{n} s+\lambda\right)}{\bar{K}_{n}} \widehat{c}_{n}(s, z)=-\frac{\bar{u}_{n}}{\bar{K}_{n}} \bar{c}_{n}^{y}(0, z)
\end{aligned}
$$

where $\widehat{c}_{n}(s, z)=L_{p}\left\{c_{n}^{y}\left(x^{*}, z\right) ; x^{*} \rightarrow s\right\}$, which has the wellknown solution (for details see work of Moreira et al. (2006)):

$$
\begin{aligned}
& \widehat{c}_{n}(s, z)=A_{n} e^{R_{1}^{n} z}+B_{n} e^{R_{2}^{n} z}+ \\
& \frac{Q}{R_{3}^{n}}\left(e^{R_{1}^{n}\left(z-H_{s}\right)}-e^{R_{2}^{n}\left(z-H_{s}\right)}\right)
\end{aligned}
$$

where

$$
\begin{aligned}
& R_{1}^{n}=\frac{1}{2} \frac{\bar{w}_{e}^{n}}{\bar{K}_{n}}+\frac{1}{2}\left[\left(\frac{\bar{w}_{e}^{n}}{\bar{K}_{n}}\right)^{2}+\frac{4\left(\bar{u}_{n} s+\lambda\right)}{\bar{K}_{n}}\right]^{1 / 2} \\
& R_{1}^{n}=\frac{1}{2} \frac{\bar{w}_{e}^{n}}{\bar{K}_{n}}-\frac{1}{2}\left[\left(\frac{\bar{w}_{e}^{n}}{\bar{K}_{n}}\right)^{2}+\frac{4\left(\bar{u}_{n} s+\lambda\right)}{\bar{K}_{n}}\right]^{1 / 2}
\end{aligned}
$$

and

$$
R_{3}^{n}=\left[\left(\bar{w}_{e}^{n}\right)^{2}+4 \bar{K}_{n}\left(\bar{u}_{n} s+\lambda\right)\right]^{1 / 2}
$$

Finally, a linear system for the integration constants is generated by applying the interface and boundary conditions. Henceforth, the concentration is obtained by numerically inverting the transformed concentration:

$$
\begin{aligned}
& c_{n}^{y}\left(x^{*}, z\right)=\frac{1}{2 \pi i} \int_{i-\gamma \infty}^{i+\gamma \infty} e^{s x^{*}}\left[A_{n} e^{R_{1}^{n} z}+B_{n} e^{R_{2}^{n} z}+\right. \\
& \left.\frac{Q}{R_{3}^{n}}\left(e^{R_{1}^{n}\left(z-H_{s}\right)}-e^{R_{2}^{n}\left(z-H_{s}\right)}\right) H\left(z-H_{s}\right)\right] d s
\end{aligned}
$$

where $H\left(z-H_{s}\right)$ is the Heaviside function. The integration constants $A_{n}$ and $B_{n}$ are previously determined by solving the linear system resulting from the application of the boundary and interfaces conditions. Due to the complexity of the integrand, the line integral in Eq. (19) is evaluated numerically using the Fixed Talbot (FT) algorithm (Abate and Valkó, 2004). This procedure yields the following:

$$
\begin{aligned}
& c_{n}^{y}\left(x^{*}, z\right)=\frac{r}{M^{*}}\left[\frac{1}{2} \bar{c}_{n}^{y}(r, z) e^{r x^{*}}+\right. \\
& \sum_{k=1}^{M^{*}-1} \operatorname{Re}\left[e^{x^{*} S\left(\theta_{k}\right)} \bar{c}_{n}^{y}\left(s\left(\theta_{k}\right), z\right)\left(1+i \tau\left(\theta_{k}\right)\right)\right]
\end{aligned}
$$

where

$$
\begin{aligned}
& s\left(\theta_{k}\right)=r \theta(\cot \theta+i), \quad-\pi<\theta<+\pi \\
& \tau\left(\theta_{k}\right)=\theta_{k}+\left(\theta_{k} \cot \theta_{k}-1\right) \cot \theta_{k}
\end{aligned}
$$

and

$$
\theta_{k}=\frac{k \pi}{M^{*}}
$$

Moreover, $x^{*}$ is defined by Eq. (14), $r$ is a parameter based on numerical experiments $\left(r=2 M^{*} / 5 x^{*}\right)$ and $M^{*}$ is the number of terms in the summation.

The stepwise approximation of a continuous function converges to the continuous function when the individual steps in the approximation approach zero. For this study, it is necessary to choose an appropriate number of sub-layers by considering the smoothness of the functions for $K, u$ and $w$. The solution obtained is semi-analytical in the sense that the only approximations considered along its derivation are the stepwise approximation of the coefficients and the numerical Laplace inversion of the transformed concentration. Therefore, this model preserves the beauty of a solution of the advection-diffusion equation without compromising the accuracy of the wind speeds and the eddy diffusivity to compute the concentration.

\section{Numerical Results}

To illustrate the aptness of the formulation discussed for simulating contaminant dispersion in the ABL, the performance of the solution is evaluated hereafter. The present study primarily focuses on the concentration distribution of air contaminants in a given region under the influence of large-scale and mesoscale winds. The mesoscale winds are chosen to simulate local winds produced by urban heat island effects. The profiles of large-scale winds, mesoscale winds and the eddy diffusivity that are defined in Eqs. (4), (5), (6), (7) and (8) include several unknown parameters, i.e., $u_{r}, z_{r}, a, \alpha, w *$ and $h$. Therefore, these parameters are required as input to calculate the concentrations using the proposed scheme. The following values are assumed: $u_{r}=3 \mathrm{~m} / \mathrm{s} ; z_{r}=10 \mathrm{~m}$, and $a=0,002 \mathrm{~s}^{-1}$. Moreover, the values of the other unknown parameters, i.e., $\alpha, w_{*}$ and $h$, are de- 
termined according to the stability conditions. In this work, only unstable atmospheric conditions are considered. Therefore, the following constants are assumed in the simulations performed: $\alpha=0.17$ (Agarwal and Tandon, 2010), $w_{*}=1 \mathrm{~m} / \mathrm{s}$ and $h=500 \mathrm{~m}$. The parameters above are chosen to represent a "light large-scale wind". Thus, a comparatively low value of $u=3 \mathrm{~m} / \mathrm{s}$ is used for the large-scale wind at $10 \mathrm{~m}$. The value of $\alpha$ was chosen to produce wind speeds in the region of interest that do not exceed the large-scale wind speeds. The contaminants are assumed to be emitted at a constant rate from a line source over an urban region. The simulated region extends from the origin and lies within the range of validity, i.e., $0<x<u_{r} / a(\sim 1500 \mathrm{~m})$.

It is assumed that the removal of contaminants occurs via ground absorption (dry deposition) and chemical reactions; these processes are defining the parameters $V_{d}$ and $\lambda$, respectively. For the purposes of this study, $V_{d}=0.6 \mathrm{~cm} / \mathrm{s}$ and $\lambda$ ranges from 0 to $10^{-4} \mathrm{~s}^{-1}$.

Figure 1 shows the numerical convergence of the proposed solution for the nondimensional ground-level concentration $\left(C=c^{y} u h / Q\right.$, where $u=u_{r}$ for all simulations performed) at various dimensional distances from the source $(x=100,300,500,800$ and $1200 \mathrm{~m})$ for an increasing number of terms in the summation $\left(M^{*}\right)$.

Figure (1a) shows convergence for simulations without mesoscale winds, while Fig. (1b) shows convergence for simulations with mesoscale winds. From these figures, $M^{*}=50$ provides good accuracy for both cases. With the increase of the number of terms in the numerical integration the solution stabilizes in a fixed value, that is, converges to one value, obeying certain numerical convergence criteria.

To obtain insight into the distribution of contaminants in a region that is simultaneously affected by both largescale and mesoscale winds under unstable atmospheric conditions, the computed concentrations are shown in Figs. (2-7). The analysis considers the contaminant concen-

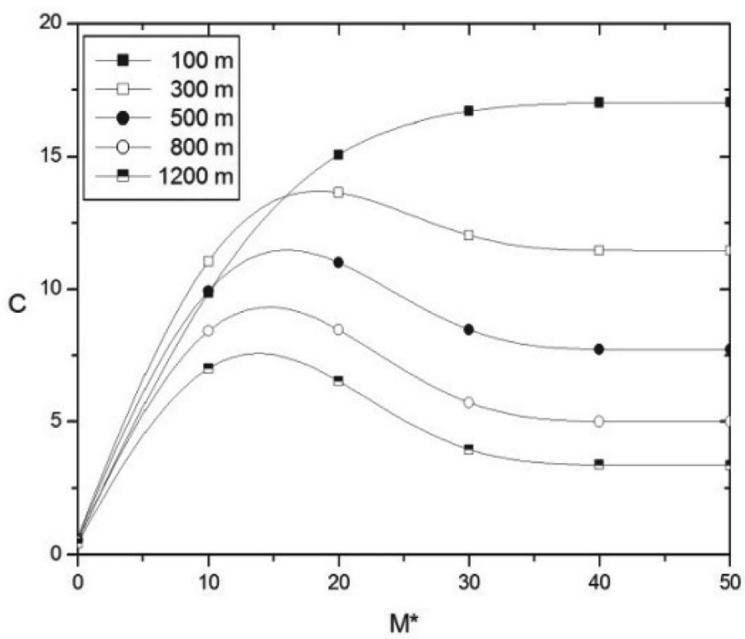

tration distributions both with and without mesoscale winds to clearly visualize the effect of urban heat island on contaminant dispersion.

Figure 2 presents the isolines of the nondimensional concentrations $\left(C=c^{y} u h / Q\right)$ as a function of the nondimensional distance $X(X=x w * / u h)$ and the nondimensional height $Z(Z=z / h)$ for a ground-level source. Figure (2a) shows the concentrations without mesoscale winds, while Fig. (2b) shows the concentrations with mesoscale winds.

An analysis of the results demonstrates the effects of the mesoscale winds on contaminant dispersion. For the case shown in Fig. (2b), the concentrations increase as the nondimensional source distance increases.

Figure 3 presents the isolines of the nondimensional concentrations as a function of the nondimensional distance with a source at $z / H_{s}=0.2\left(H_{s}=100 \mathrm{~m}\right)$. Figure (3a) shows the concentrations without mesoscale winds, while Fig. (3b) shows the concentrations with mesoscale winds.

Again, the effects of the mesoscale winds on contaminant dispersion can be observed in the results. Figure (3b) shows that the concentrations increase as the nondimensional source distance increases.

Figure 4 shows the resulting vertical profile of the contaminant concentrations for a ground-level source at different distances from the source for the cases (a) without mesoscale winds and (b) with mesoscale winds.

According to Fig. 4, there is a greater tendency towards vertical homogenization in the contaminant concentrations for the case with mesoscale winds.

Figure 5 shows the effect of deposition for different distances ( $x=100 \mathrm{~m}$ and $1400 \mathrm{~m}$ ) and considering simulations with mesoscale winds and without mesoscale winds.

According to Fig. 5, for distances closer to the source $(x=100 \mathrm{~m})$, dry deposition has less effect on the vertical profile concentrations for both scenarios. However, for greater distances from the source $(x=1400 \mathrm{~m})$, the depend-

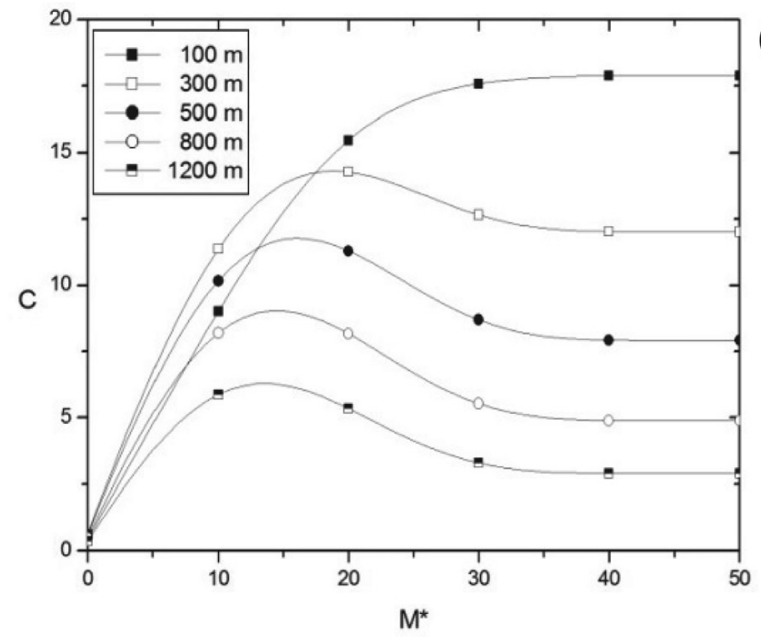

(b)

Figura 1 - Convergence of the solution for dimensional source distances $x=100,300,500,800$ and $1200 \mathrm{~m}$ (a) without mesocale winds and (b) with mesoscale winds (ground-level source). 

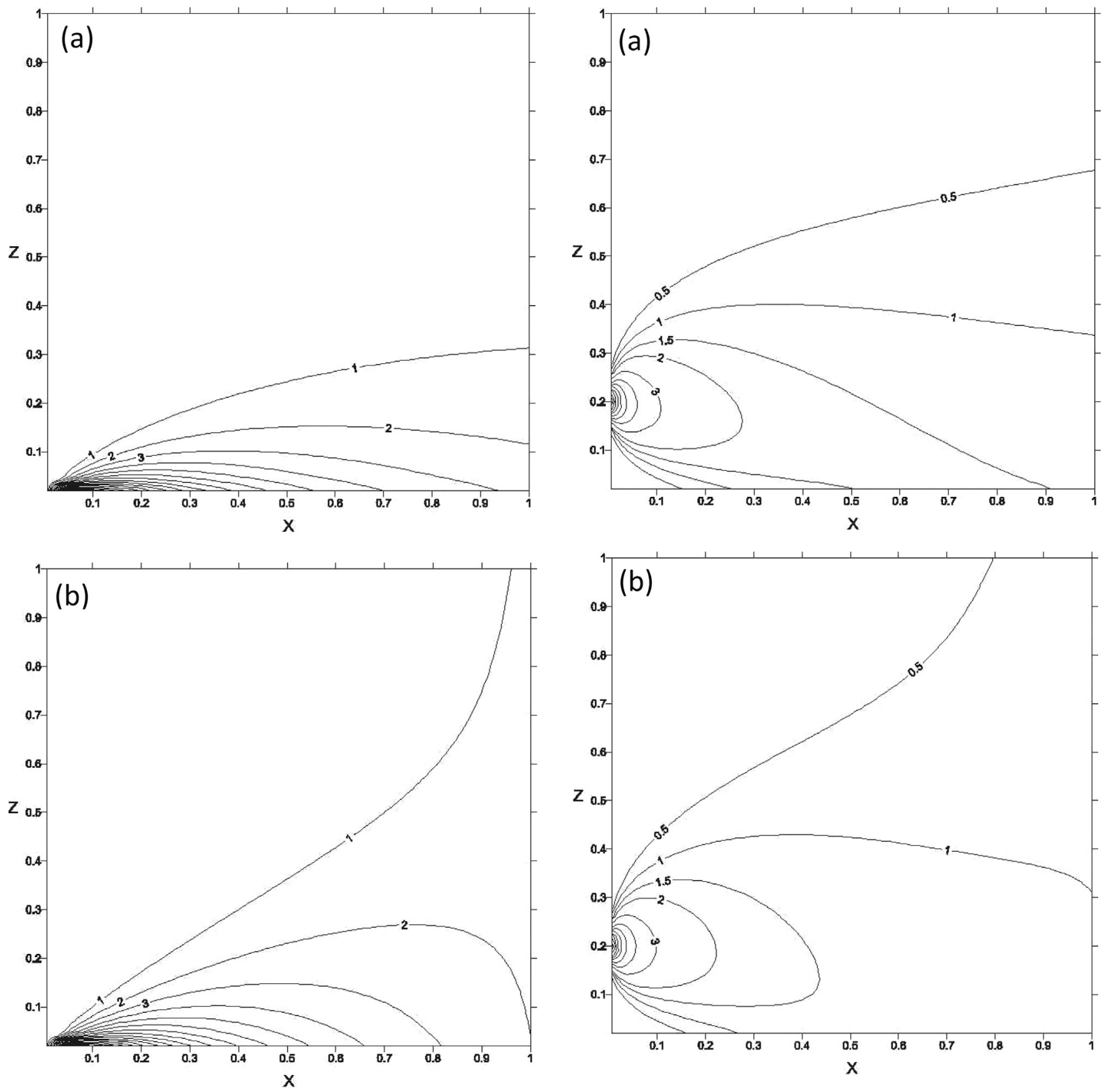

Figura 2 - Isolines of the nondimensional concentrations $\left(C=c^{y} u h / Q\right)$ as a function of the nondimensional distance $(X=x w * / u h)$ and the nondimensional height $(Z=z / h)$ (ground-level source), (a) without mesoscale winds and (b) with mesoscale winds.

ence on dry deposition is more evident in the vertical profile concentrations when considering the effect of mesoscale winds.

Figure 6 shows the effect of chemical reactions $(\lambda=0$, $10^{-3}, 10^{-2}$, and $10^{-1}$ ) on the nondimensional concentrations $v s$. the nondimensional distance from the source at the surface.

According to Fig. 6, the maximum concentration is greater in the case with mesoscale winds. Moreover, the concentrations decrease more rapidly as the distance from

Figura 3 - Isolines of the nondimensional concentrations $\left(C=c^{y} u h / Q\right)$ as a function of the nondimensional distance $(X=x w * / u h)$ and the nondimensional height $(Z=z / h)$ (source at $\left.z / H_{s}=0.2\right)$ (a) without mesoscale winds and (b) with mesoscale winds.

the source increases despite the fact that $\lambda$ is an order of magnitude smaller than in the case without mesoscale winds.

These figures are drawn with and without mesoscale winds; the results show that the concentration of air contaminants is intensified due to the effects of mesoscale winds. These illustrations also show that the contaminant concentrations increase in the presence of mesoscale winds even at relatively high levels (especially compared with the case without mesoscale winds). The mesoscale winds circulate the contaminants and move the contaminants up- 

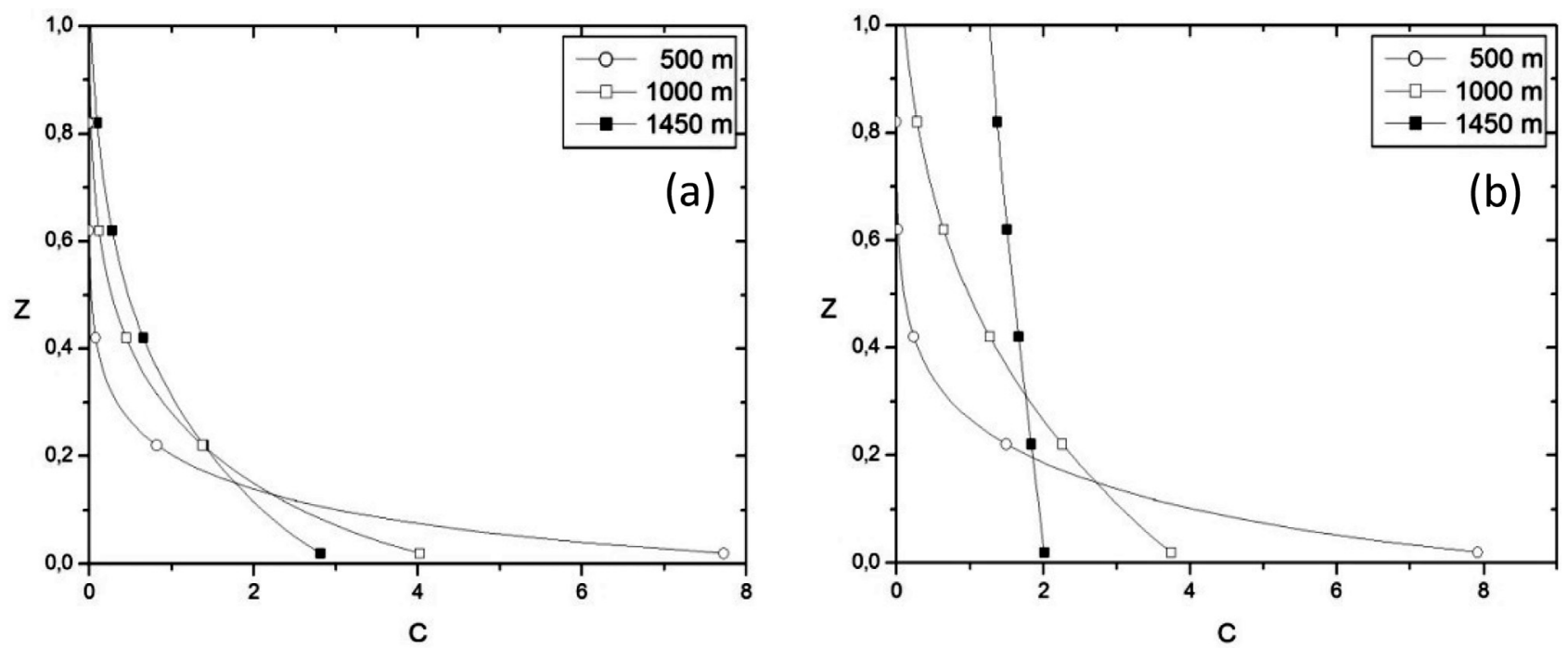

Figura 4 - Vertical profile of the concentrations $\left(C=c^{y} u h / Q, Z=z / h\right)$ for dimensional distances $x=500,100$ and $1450 \mathrm{~m}$ (a) without mesoscale winds and (b) with mesoscale winds.
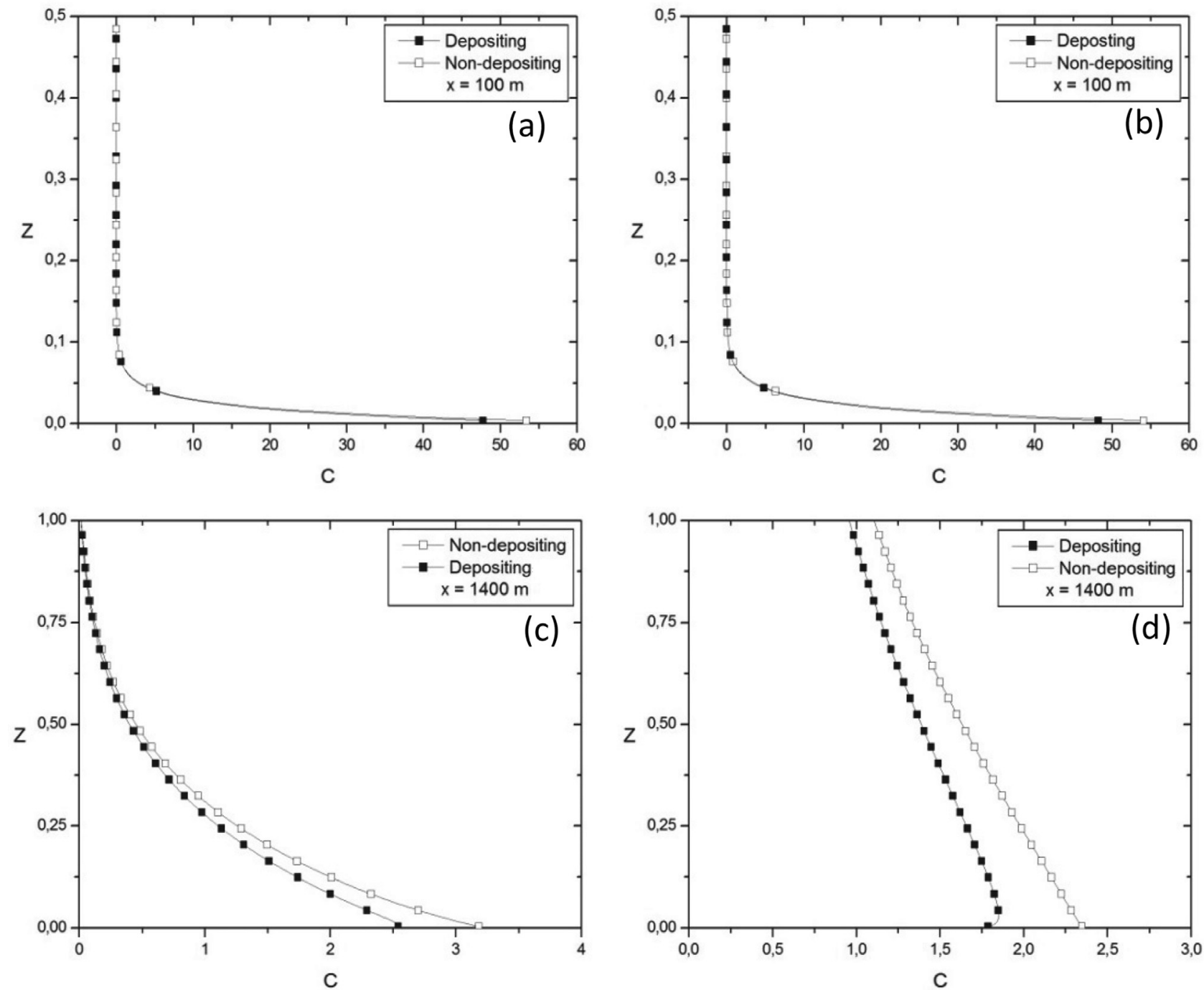

Figura 5 - Vertical profiles of the nondimensional concentrations with and without mesoscale winds for distances from the source of 100 and $1400 \mathrm{~m}$. Figures (a) and (c) do not consider mesoscale winds; (b) and (d) consider mesoscale winds. 

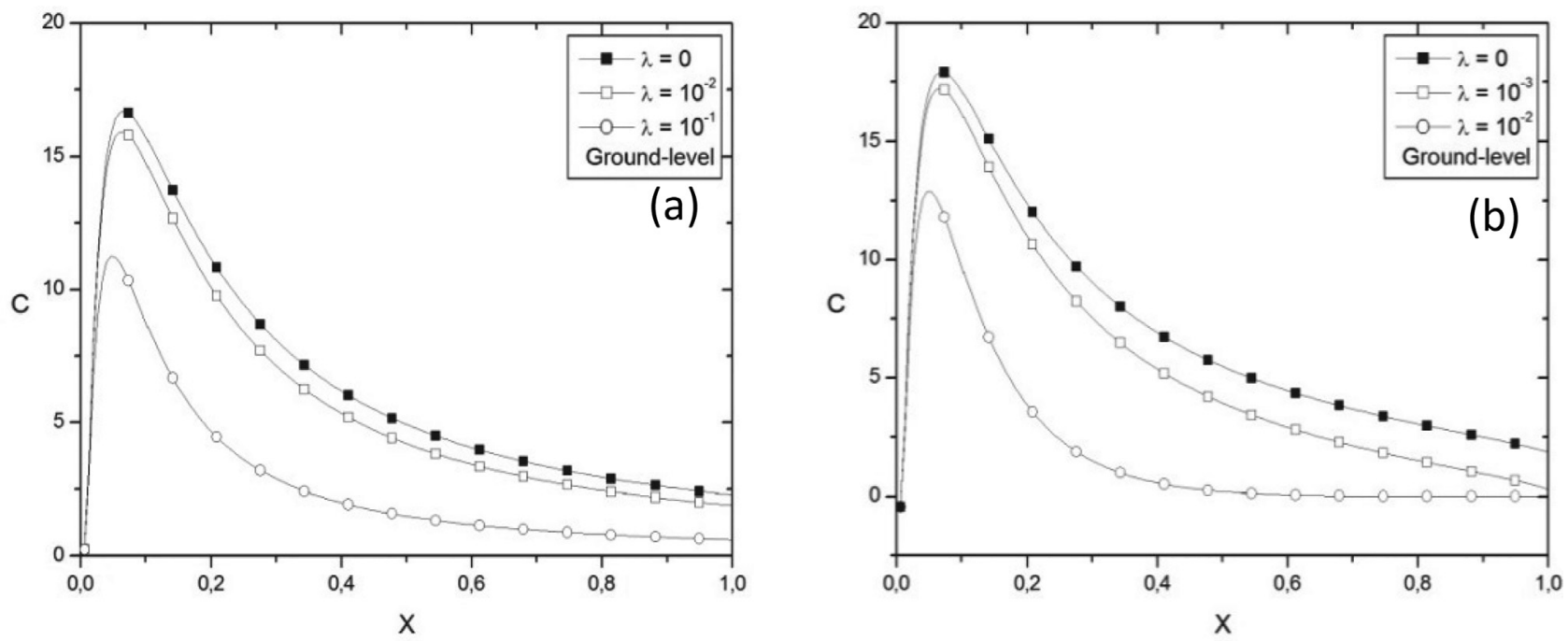

Figura 6 - Nondimensional ground level concentrations as a function of the distance from the source for different $\lambda$ (a) without and (b) with the effects of mesoscale winds.

ward, which results in a negative effect on the surrounding area.

\section{Summary and Conclusion}

An integral semi-analytical solution to the two-dimensional advection-diffusion equation using an integral transform method and considering the longitudinal wind speed as a function of both $x$ and $z$ variables is presented. No approximations are made during the derivation of the solution except for the stepwise approximation of the parameters and the Laplace numerical inversion required by the FT scheme. The solution suggests that mesoscale winds have an effect on contaminant dispersion. The mesoscale winds are chosen to simulate local winds produced by urban heat island effects. The simulations discussed in the present paper clearly demonstrate that the mesoscale winds produce vertical transport that increases the contaminant concentrations. This effect occurs at locations downstream from the source where the large-scale and mesoscale winds are opposite in the horizontal direction. In reality, when the heat island effect is large, the longitudinal eddy diffusivity can be neglected. This factor may influence the contaminant concentrations in areas close to the source; a more thorough analysis on this topic is needed in future studies.

Today, air pollution problems are not treated in the manner described in the present paper. There are various air pollution situations that require the use of complex mesoscale models to properly describe the dispersion processes and properly represent the relevant chemistry and emission processes. Complex models, such as the CMAQ model (the Community Multiscale Air Quality model), have been designed to simulate air quality by including state of the art techniques for modeling multiple air quality issues. However, in complex models, increasingly more processes, such as sea breeze circulations, urban heat islands, and waves, are represented. Therefore, these models are often perceived as black boxes that cannot easily represent the effects of individual processes on air quality. Apart from this, for many policy and scientific applications on air quality modeling, it is desirable not only to know the contaminant concentrations that would result from a certain situation but also the extent to which those concentrations would change under various perturbations.

It is important to mention that analytical and semianalytical solutions are fundamentally important for understanding and describing physical phenomena because they account for all parameters in a problem and provide a means for investigating their effects. Moreover, air pollution models have two types of errors. The first type is due to the physical modeling. The other type is inherent to the numerical solution of the equations associated to the model. Henceforth, it is possible that analytical and semi-analytical solutions may at least partially mitigate the error associated with mathematical models. As a consequence, the model errors somehow restrict the physical modeling error.

Therefore, the model proposed herein helps in understanding one of these processes, i.e., urban heat island effects, by allowing control over meteorological parameters. Hence, it is easy to represent the steering factors for such a phenomenon and to test its sensitivity against changes in atmospheric conditions. The results of the proposed semianalytical model can help to increase the confidence in complex model predictions and identify specific variables, e.g., the wind field and atmospheric stability, that should be investigated more closely in complex modeling studies.

\section{Acknowledgments}

The author thanks CNPq for the partial financial support for this study. 


\section{References}

ABATE, J.; VALKÓ, P.P. Multi-precision Laplace transform inversion. Int. J. for Num. Methods in Engineering, v. 60, p. 979-993, 2004.

AGARWAL, M.; TANDON, A. Modeling of the urban heat island in the form of mesoscale wind and its effect on air pollution dispersal. Applied Mathematical modeling, v. 34, p. 2520-2530, 2010.

CHANDLER, T.J. Discussion of the paper by MARSH and FOSTER. The bearing of the urban temperature field upon urban pollution patterns. Atmos. Environ., v. 2, p. 619-620, 1968.

CRANK, J. The Mathematics of Diffusion. Oxford University Press, 414pp, 1979.

DEGRAZIA, G.A.; CAMPOS VELHO, H.F.; CARVALHO, J.C. Nonlocal exchange coefficients for the convective boundary layer derived from spectral properties. Contr. Atmos. Phys., v. 70 p. 57-64, 1997.

DEMUTH, C. A contribution to the analytical steady solution of the diffusion equation for line sources. Atmos. Environ., v. 12, p. 1255-1258, 1978.

DILLEY, J.F.; YEN, K.T. Effect of a mesoscale type wind on the pollutant distribution from a line source. Atmos. Environ., v. 6, p. 843-851, 1971.

GRIFFITHS, J.F. Problems in urban air pollution, in: AIAA 8th Aerospace Science Meeting, AIAA, Paper No. 70-112, New York, 1970.

LAKSHMINARAYANACHARI, K.; SUDHEER PAI, K.L.; SIDDALINGA PRASAD, M.; PANDURANGAPPA. C. A two dimensional numerical model of primary pollutant emitted from an urban area source with mesoscale wind, dry deposition and chemical reaction. Atmospheric Pollution Research, v. 4, p. 106-116, 2013.

LIN, J.S.; HILDEMANN, L.M. A generalised mathematical scheme to analytically solve the atmospheric diffusion equation with dry deposition. Atmos. Environ., v. 31, p. 59-71, 1997.

MOREIRA, D.M.; TIRABASSI, T.; CARVALHO, J.C. Plume dispersion simulation in low wind conditions in stable and convective boundary layers. Atmos. Environ., v. 39, p. 3643-3650, 2005a.

MOREIRA, D.M.; VILHENA, M.T.; TIRABASSI, T.; BUSKE, D.; COTTA, R.M. Near source atmospheric pollutant dis- persion using the new GILTT method. Atmos. Environ., v. 39, p. 6290-6295, 2005b.

MOREIRA, D.M.; VILHENA, M.T.; TIRABASSI, T.; COSTA, C.P. Simulation of pollutant dispersion in the atmosphere by the Laplace transform: the ADMM approach. Water, Air and Soil Pollution, v. 177, p. 285-297, 2006.

MOREIRA, D.M.; VILHENA, M.T. Air Pollution and Turbulence: Modeling and Applications. 1. ed. Boca Raton: CRC Press, 354pp, 2009.

MOREIRA, D.M.; VILHENA, M.T.; TIRABASSI, T.; BUSKE, D.; COSTA, C.P. Comparison between analytical models to simulate pollutant dispersion in the atmosphere. Int. J. Environ. Waste Management, v. 6, p. 327-344, 2010.

MOREIRA, D.M.; MORAES, A.C.; GOULART, A.G.; ALBUQUERQUE, T.T. A contribution to solve the atmospheric diffusion equation with eddy diffusivity depending on source distance. Atmos. Environ., v. 83, p. 254-259, 2014.

NIEUWSTADT, F.T.M. An analytical solution of the timedependent, onedimensional diffusion equation in the atmospheric boundary layer. Atmos. Environ., v. 14, p. 13611364, 1980.

NIEUWSTADT, F.T.M., DE HAAN, B.J. An analytical solution of one-dimensional diffusion equation in a non-stationary boundary layer with an application to inversion rise fumigation. Atmos. Environ., v. 15, p. 845-851, 1981.

OKE, T.R. Boundary Layer Climates, Routlegde, Taylor and Francis Group, pp. 81-107, 1995.

ROUNDS, W. Solutions of the two-dimensional diffusion equation. Trans. Am. Geophys. Union, v. 36, p. 395-405, 1955.

SCRIVEN, R.A.; FISHER, B.A. The long range transport of airborne material and its removal by deposition and washout-II. The effect of turbulent diffusion. Atmos. Environ., v. 9, p. 59-69, 1975.

SHARAN, M.; SING, M.P.; YADAV, A.K. A mathematical model for the atmospheric dispersion in low winds with eddy diffusivities as linear function of downwind distance. Atmos. Environ., v. 30, p. 1137-1145, 1996.

VAN ULDEN, A.P. Simple estimates for vertical diffusion from sources near the ground. Atmos. Environ., v. 12, p. 2125 2129, 1978.

All the contents of this journal, except where otherwise noted, is licensed under a Creative Commons Attribution License CC-BY. 